\title{
As Beginners: How We Feel About Ethnography
}

\author{
Yuhong Chen ${ }^{1 *}$ Jie Min $^{2}$ \\ ${ }^{1}$ Chengdu No.7 High School International Department, Chengdu, 610000, China \\ ${ }^{2}$ Chinese International School, Hong Kong S.A.R, China \\ *Correspond author email: 1942264339@qq.com
}

\begin{abstract}
The field note of Ethnography is about to observe the social phenomenon that whatever the authors are interested in. It is all about the process of graduate forming thoughts and how people are truly analyzing a certain phenomenon according to behaviors instead of stereotype. During and after a six-weeks course of ethnography, we record what we observed certain phenomena that we are interested in and generate some thoughts and findings. Also, we reflected the methods that we used and analyzed the importance of our findings. As the learners of this course, we also focused a lot on the paperworks done by the former scholars in this domain as our background of our work. The purpose of this paper/reflection is to provide the public with a unique perspective of beginners to ethnography, as well as to record our first step in the journey of society observation.
\end{abstract}

Keywords: ethnography, learning experience and reflection, slow forming thoughts, observe details

\section{INTRODUCTION}

"The clerk's face was changing according to the person he met." That was what my friend said during the observation in the day.

On the afternoon of July 21st, I went to the English institution to consult about their classes in order to join my friends for study. As I went in, I could see the interior of this organization, it was large with dozens of classrooms. The whole classroom area was divided into two parts, the small classroom on the left and the large classroom on the right. The left part contained 18 separate classrooms evenly distributed in two aisles while the right part was randomly distributed. Connecting the left and right parts was a relatively large rest area. In fact, I was the second to consult. There was an old woman in front of me. The staff asked me to wait in the rest area at the door. Because they left the door open, I could pretty much see and hear what they were doing and talking. There were many conspicuous wrinkles on the woman 'face. She was wearing a gray outfit, black trousers with a little discoloration, the knee part of the pants was even washed white, and a black boots without heels. Her black hair is mixed with a few silver strands. Nest to her was a girl wearing a black hat and a white T-shirt with a flower on the back and a pair of blue jeans, simple but stylish, browsing the video with frowning. The woman seemed to be her mother according to the ages. The receptionist asks, "what do you want to know?" The woman seemed to be a little hesitant about what to say next. "How much is the cheapest class you have here for an hour?" She finally asked. Hearing this sentence, the receptionist's face changed in an instant. She frowned and rolled her eyes a little bit. "500 an hour." she said it in a casual tone while grinding her nails. However, the "mother" opened her mouth in surprise, "500 for just an hour? That is insane!" "Mom, nowadays price of cram school is already this expensive, five hundred an hour sounds fair to me. After all, all my friends come here for extra study." She waved her arm as she states her point excitedly. "You are embarrassing me." Then the girl left the room. I can see exactly that the corners of his mother's mouth tremble as her daughter talks. When it was my turn, I consult their SAT courses and teachers. The receptionist patiently explained it to me, but I am nor listening carefully. Instead, I was observing the expression on her face. To my surprise, she did not treat me as she did to the last guest. Instead, she was smiling at me all the time and even took a piece of paper to record my questions in order to answer them. I was surprised that staffs could treat people with entirely two different attitudes.

After all that, I decided to go to the coffee shop Starbucks to enjoy some friends time with $\mathrm{KC}$ there. The whole coffee shop is made of wood, giving people a sense of elegance. I also see a lot of tables and chairs in different 
shapes, some of them are for two people, and the others are tables for four. All tables are in the color of dark brown and the chairs are light brown. A group of students in school uniforms came in. They went to the counter and shouted for the staffs, which attracted my attention, but the staffs did not come for them. Instead, one of them even rolled his eyes. This phenomenon reminds me of what I see in the English institution, so I decided to order something myself. As I approached, two old women with clothes in black happened to be in front of me. One of them asked the staff: "What would you recommend drinking?" The clerk spoke something quickly about their new products. The two women began to discuss what to drink. They basically turn over the menu and asks about the sweetness and taste of basically all drinks. The women still hadn't decided what to drink yet. That was the moment that the clerk became irritated answering the questions. He crosses his waist and turns his eyes a little and asks: "What you want to drink exactly?" The women were still considering it. After two minutes menu checking, they finally decided what they want. Starbucks did not have a small cup; the middle cup is equal to their small one. The two women asked the clerk how to order a small cup. The clerk explained to them and sighed. When they paid, he just scants their code quickly and let them wait aside. When it was my turn, I ordered a cup of coffee that was the same as the two of them. But the clerk smiled at me and recommended their set meal to me which could buy a cake for only a plus of 10 yuan. I was really surprised at this attitude changing again and that's why $\mathrm{KC}$ said those words that I wrote in the beginning of passage.

\section{RESEARCH BACKGROUND}

The journey of field note writing wasn't easy for me due to my need for quarantine. For week 1 I went to a great restaurant located at the top floor of a Hong Kong hotel, and just a week later my vision got limited in a dim 20-meter squared quarantine hotel room. Despite my lack of opportunity in investigating a setting in depth, as a beginner to ethnography, the three weeks-field notewriting experience was sufficient in terms of introducing me into the fresh world of ethnography and giving me a taste of its unique research methods.

\section{LITERATURE REVIEW}

\subsection{Vignette from Week 1}

The two women also speak to each other but their voices are lower than the man so I can't hear clearly. The younger woman's movement is slow and soft when she is holding the bowl with one of her hands and using the other to pass the soup into her mouth scoop by scoop. (She acts naturally so I think she is from a family that requires proper manners.) "Got to keep my running schedule". The man says to the old man, who seems to eat more than the rest as he rarely talks. When he is eating, he uses one hand to lift the bowl by holding its bottom, and another hand to scoop the food in the bowl to her mouth. He would also bend his back to keep his mouth closer to the bowl. Compared to the lady, his movement is relatively big and fast. Occasionally, the older woman would look outside the window for a while, then lowers her head to scroll her phone. She sometimes passes the phone to the younger woman, who takes it, replies to something, and passes back the phone. (The old man looked at me several times, probably because I keep writing something on my phone after looking at them, and even holding up my phone toward their table. He might think I am a creepy little girl spying on them but actually I'm completing my work and trying to take photos of the amazing view.)

\subsubsection{Reflection}

This is my first week field note which was written in a luxurious restaurant. I would say "confusion" was the main theme of my first observation. As a student has been required to follow the sundry and fixed rules of essay writing for a long time, the flexibility of ethnographic field notes made me quite uneasy. During the whole process, various questions were occupying my mind. What should I start with? How much is enough for the site description? How detailed should I go for in order to produce a "rich" observation? Who/which group of people should I focus on? Should I write while observing or take videos then write notes based on them? Failing to answer these questions immediately, what I could do was to record everything I sensed with as many details as possible. What I found hardest during this process is the selection of information. I could only observe for 20 minutes maximumly, yet I needed to include description on both the environment and the human interactions. The design of the restaurant seemed simple but had a lot of exquisite details (such as the pattern on the wall); there were nt a lot of customers, yet each table had different types of interaction (couples, family, co-workers). After minutes of thinking, I decided to follow a basic logic for the site description and chose one table to focus on after a general observation, and the vignette I selected above is the final choice of mine. At this point, when I'm looking back to my very first filed note, I realized that I should've been more emerged into the setting. I should not rush into the observation but do it mindfully. I should first be a guest of the restaurant which is the most natural identity, and then merge the observation into the behavior of a customer. I think, in that way, possibly the old man would not be that skeptical of my actions and would enact more interaction with his family members, as a result, enriching my vignettes.

\subsubsection{Research Question 1}

On my way home, the questions generated from the 
experience in English institution and Starbucks popped to my mind: How do the ages, wearing and their conversation brevity of consumers influence the attitude of the staffs? What kind of customers attract clerks? Do different customers elicit different sales responses? Although I've been in the social content many times, I did not pay attention to all these. Consequently, I was surprised for what I observed. Based on the phenomena that I observed above that different groups of people can change the attitude of the staffs; I can't help thinking about the reasons behind this phenomenon. The research questions are particularly crucial in ethnographic works, so a good question must be related to the phenomenon that the observer perceives. These phenomena do arouse my interests, but I didn't have a specific question because I actually observe these phenomena in different settings. It is hard to be generalized one single question.

\subsubsection{Research Questions 2}

Although I'm still struggling with forming a correct ethnographic research question, I can already sense the great difference it has with those of other subjects. For example, when I'm writing a physics report, I always start with a specific research question that explicitly states the relationship between two variables explicitly. For instance, "for an object moving down a slope, how does the height of the slope affect the time used"? However, in ethnography, researchers ask "how" questions about social and cultural processes, but not about "effects" or outcomes or impacts. I learned this lesson from my third week's field note which was about quarantine and productivity. In the field note, I started my interview naturally with a research question in mind - how is productivity affected by the environment and daily schedule? The question turned out to be non-ethnological. Yes, I did ask the "how" question, but my question assumed the "effect" relationship between the environment and productivity. For my future ethnographic research, I will avoid making the same mistakes.

\subsection{Research Background 1}

From the book of Children and Gender [1], the author Thorne connected her filed note with her previous fieldwork and made comparison with her childhood to emphasize the changes in gender relationship by analyzing the way they play, including some stereotype that people might have towards the play of children. Also, the writer includes a section of problems that she encounters and the solutions for them. The book of How I Learn What a Crock Was [2] is even more interesting for me due to the reason that it is like an attractive story, picturing the whole process of the author's learning by illustrating every details, from how he studied there and his confusion of what to study at the first place. His ethnographic work thoroughly described the experience of him studying in a medical school by a specific story line.

After finishing reading them, I learn a lot from these two materials. The book Children and Gender have given inspiration to my fieldwork which I will conduct later this year. I can compare my previous experience and my observation in order to notice the bias that exists in people's mind. Linking the phenomena with thoughts is a good means to help come up with questions. I will certainly apply this method to my fieldwork. Also, it lets me know that encountering problems in ethnographic work is common, and it can be recorded in the work itself as well, like what I am writing now. I can tackle these problems with a positive attitude. I learn how to write a intriguing introduction from the work of Howard Becker by telling stories (which I already applied in my introduction). From the passage of Gender Replay, the author keeps mentioning her teacher's impact on her work, which reminds me that ethnography is a process to get progress and learn from the experience of observing. I am also a new learner of this field. It gives me confidence of not scaring the whole process of ethnography.

\subsubsection{Children and Gender", Thorne [1]}

In this article, Thorne exemplifies a perfect ethnography introduction and reshapes the conventional understanding of "gender". Thorne began the book with an ethnographic description of a playground which was occupied by children and compared the scene with that of what she had seen as a child. She explains how the gender itself "social construction" and children is actually "socialized" into specific gender characteristics, from which she brings out her own interest in studying children and gender, that is, the power children exude through their behaviors, which can mutually affect them and influence the adults. She suggests that children should be taken as seriously as adults, which is part of the reason why she conducts this ethnographic research. After the "hook" and the related research, Thorne proceeds to her experience of studying children in elementary schools. In this section, she begins with an overview of the study then talks about some dilemmas she faced, such as struggling to find a correct word that has limited gender colors and appropriate from the children's perspective to describe her observants. Eventually, Thorne explains the influence she wishes to obtain through this group, that is, to "show the value of ethnography in illuminating connection of gender, and age, to other lines of difference and inequality."

\subsubsection{Reflection}

If I'm planning to write an ethnography research proposal, I believe "Children and Gender" would be a very useful guide for me to write the introduction. Thorne 
perfectly demonstrates how to begin with a story that attracts the readers, then transits smoothly to the main topic and its related background studies. She also talks about her methods and some difficulties she faced in full consideration and with understandable languages, allowing me to follow through easily. Not only does Thorne exhibit her excellent writing skills, her thoughtprovoking ideas of gender also widen my perspective and make me reconsider my understanding of gender. When she mentions her childhood memory, I also looked back and realized how lucky was I that I wasn't restricted by the "gender box" but allowed to do things that were not "girly". Furthermore, this is quite beneficial to the formation of my personality which both includes the powerful and the mental sides, and this is due to how my parents avoid influencing me based on the conventional understanding of what a "boy" or "girl" should be like.

\subsubsection{How I Learned What a Crock is", Howard $S$, Becker [2]}

Summary: In this reading, Becker vividly tells a story of how he was confused about his work in the medical school to the final understanding of "what a crock is". Overall, the story is very easy-to-read, yet it shows a very complete mini ethnography research, especially its methods including observation and interviews. Like a lot of ethnographers, Becker entered his field site with no specific research question in mind. In the beginning he just aimlessly followed the students from place to place, until he heard a student describe a patient with the word "crock". Out of confusion and curiosity, he asked the meaning of the word, yet the answers were relatively blurry. Therefore, he began to go deeper by asking more questions and observing more. Eventually, not only did he figure out the meaning of "crock", but also reveal some interesting motives of the medical students.

Reflection: Personally, this is my favorite reading and I think it would be a great material to put into the course introduction because it efficiently raises my interest in ethnography. From this story, I learned about the freedom of ethnographic writing as Becker's language is very casual. I also got an insight into the value of ethnography. After reading, my understanding of this subject is that it highly focuses on the root of people's behavior and interaction. It seems like research that begins with "how" questions to "why" questions. In "How I learn What a Crock is," [2] Becker started with free observation then he ran into something he was interested in. I was surprised by this form of research as the former ones I've done always begin with a hypothesis, which seems to be "missing" in ethnography.

\subsection{Methods background}

In my previous observation of this project, I've tried the method of interviewing of the staff in Starbucks. I try to do this as natural as I can, and I regard this as a good method to help people fully express themselves without worrying whether their answers are ethical or not. Consequently, I can apply this method to my later fieldwork to get the real answers from people, so that it can generate the fairest answer. I will also apply the method of taking photographs to not only help myself remember, but also make my note more understandable to others as they can see the interior of the building clearly. I've wanted to apply this means to my previous field note, but I failed to do so because I was too shy to take out my phone for picture taking. I guess it is also a skill of not being embarrassed that I want to improve.

In my previous note, I also address the problem of when and where to observe as I wrote in the first one. Although I choose the site randomly basically some places with social dynamic, I do choose the time period deliberately. Going to the coffee shop in the afternoon facilitates my observation on people because it is a common sense, as I mentioned before, that people tend to go to the coffee shop during afternoon. On the other hand, choosing the time period to go to the English institution is not that easy for me because I have to weigh the pros and cons to go really early in the morning. I can get the chance to go inside to see the interior, while I will be regarded as wield because I don't have classes but hanging around in the whole building. I personally regard this embarrassing as there are teachers coming to me that day asked whether I'm finding my classrooms. I am noticeable in the spacious area without people. Also, I must stay until noon to wait for people to come for me to observe. It is not a big deal for me compared to the previous problem. The waiting time is not a issue. Instead, the biggest problem is the embarrassment that generated from the experience of going there alone and being noticed by someone else. That would be a big challenge for me to conquer.

For the methods of recording the details of the observing process, I have tried to use the voice recordings. However, it didn't work because it was noisy in the coffee shop. After returning home, I tried to hear what people are talking about, but I only heard a bunch of noisy background sounds. Since that, I abandoned the method of voice recordings. On the other hand, jottings are helpful for me. It can remind me of things that happened during the place that I observed. From the short note of hint, I can fully picture the scene that I was in during the observation. After all, I could not record everything I heard and saw at the scene, which means the jottings are needed for me. Moreover, from my previous work, I can tell that the most I can do is to ask people a few small questions which is not enough for what I really want to find out for my project. I guess one of the reasons 
is that there are customers behind me waiting for ordering, so I didn't have plenty of time to ask my questions. Another reason would be that I personally think it is awkward to ask a lot of questions, especially because I was trying to keep it natural. Asking a lot of questions might makes it feels deliberate and makes the clerk think I'm strange. In order to achieve my ideal answers, I choose to ask just two or three questions at the first time. That generates a dilemma, but I think I can overcome this one by going there more to try to make friends with the clerk, which is also difficult for me. When I am holding something that I'm interested in my mind, I might focus on phenomena that related to it more. As I'm not sure about my question and setting, I might try to do as much as possible like I was doing in my field notes before. I only went to a place one time a week in my previous fieldwork. Of course, I know that is not enough, so I'm planning to go to the site every day to really reach a certain conclusion. After all, accidental events cannot explain a social phenomenon.

Speaking of making a judgment of a certain social issue, it has to be compact, and it requires lots of time. The best thing of studying ethnography is to enjoy the slow process in mind to experience how the judgments form in people's minds. In our daily life, we are getting used to judge things easily and quickly. However, in this course, I have the chance to analyze people's behaviors in order to make a judgment. Also, I personally think this course helps me to shape my personality a little bit. I'm not a very patient person, but I have to remain patient during the whole observation in order to not miss any details. It trained my skills of concentrating for at least an hour. As a result, it develops my ability of patience. Moreover, it is interesting for me to perceive lots of social phenomena. They will provoke my curiosity in lots of social issues and make me a better person.

For the field notes I have created in the past few weeks, basic ethnographic research methods such as observation and interviews were those I employed the most. Besides, I have also used tools such as photograph, drawing, and voice recording to capture the details that I tend to ignore during the process. I will be reflecting on each of the methods separately.

\subsubsection{Observation}

“ It's only seven o'clock, so the restaurant was not filled with people yet. The restaurant isn't very big, yet the sea views the customer could appreciate easily expanded the space. Through the lines of French Windows, you can see the two sides of the ocean, on which boats in different sizes and with different functions are slowly going by. You can see the buildings reflecting the blue of the sky and the sea, as well as the orange lights themselves emit. The restaurant consisted of 15 sets of tables and chairs. Some of the tables are squared while others are round with a glass plate on it to pass the dishes around. Around each table there are four brown leather chairs. Overall, the whole restaurant is filled with wooden materials, including the floor, the cylinders, and the walls, establishing a solemn atmosphere, yet such atmosphere is then balanced out by the blue and calming scenery."

This is an extract from my first week's field note describing the environment of the restaurant. I have already discussed the difficulties I had emotionally, thus I will be reflecting on the technical aspect in this section. As you can see, the logic I followed in the writing wasn't very strict. I started with the basic information, such as the time, to some details inside and outside the restaurant, then ended up on its general atmosphere. Lacking experience, I tried to include everything I see into my field note but not choosing a focus point. Although ethnographic field note often sets a tone of the context with a setting description, I realized I have gone too detailed into it that I almost used half of the space for describing the restaurant, therefore, in my future field note, I will try to avoid over describing the fixed decoration but focused more on the people as ethnographic is studying about the social interactions and cultural characteristics. For example, when I was talking about the various groups of people in the restaurant, "I came here with my family. On other tables sat couples, friends, and business buddies." - Week 1's field note", I could have gone further to explain the process of how I distinguish these relationships.

The tool I employed for writing this field note was the memo on my phone. The strength of it was it's portable, suitable to use in the restaurant, and can record things very conveniently (typing is faster than writing and I could take photos with my phone). However, in future I will try to use paper and pencil as they provide greater freedom in terms of ways of jotting down things and recording things in various ways.

Last thing I would like to reflect on is about the choice of setting and time. Because this is the first field note, I didn't have a very clear idea on what I'm supposed to observe and which group of people am I interested in, thus, I didn't do thoughtful consideration on the type of restaurant I'd like to go (fast food, dessert shop, highclass restaurant.) and the time I go observe (weekday, weekend, morning, holiday). These things seem to be trivial yet can greatly affect the population I will be observing. For example, as I mentioned in the field note, the restaurant had a great night view outside the window, but less food served for dinner, thus if I had gone for lunch, I might have seen more food lovers instead of young girls interested in taking photos of the view. Therefore, for future research, I will conduct a detailed proposal before the actual fieldwork that specifies these variables. 


\subsubsection{Interview}

"I don't want to be the interviewee..." She already looked back to her phone and rejected, yet it didn't sound very serious, so I told her it's not formal at all and said,

"I just want to have a general idea of the situation. Cuz you know, some people prefer working at home, and others feel they are more productive in a quarantine-like setting, which type of person do you think you are?" (This time I specify my question to make it easier to answer, considering the original one might be too big that she did not know which angle she should answer from.)

"Home". She said in one second without giving any more information. So, I followed up.

"You prefer working at home because you are under someone's control, or...?"

"I'm under someone's control." She repeated my words exactly.

"So you have higher productivity?" I tried to verify.

"Ehhh, yea, but I also get more annoyed haha." She said with a short and unnatural laughter at the end.

To be honest, I was not very satisfied with the quality of my "ethnographic" interview with my sister that aims to explore how the environment of a hotel possibly shapes people's productivity and feelings. After reading the comments and James Spradley's "Asking Descriptive Questions," I summarized the following things which I can improve on in the future.

\section{- $\quad$ Purpose of interview}

Ethnographic interview is supposed to be an important qualitative method for collecting data that is often unachievable through pure observation. It should be a well-planned process in which preparation was made before the actual conversation. However, in my interview, I skipped the observation of my sister beforehand and jumped into the interview and asked questions that weren't very open. Besides, as I mentioned in the "research question" section, I conducted the interview with a strong and obvious purpose of answering my research question, and this is something I should've avoided in ethnographic research. Instead, I should stay open to observe and talk more.

\section{- $\quad$ Relationship with the informant}

As Spradley mentioned in his writing, developing a trustworthy relationship should be a careful process and its four stages are all very vital in terms of obtaining useful data from the informant. However, a mistake I made was I took the intimacy that I shared with my younger sister for granted, thus forgetting to slow down in the beginning to ask for her permission, explain my intuition, and explain her position. I think the lack of this rapport process was what hindered her from talking openly.

\section{- Interview questions}

It was after I read Spradley's work that I realized there are so many types of descriptive questions to ask, yet I used only a few and even in the wrong way. For example, I asked the question "Do you prefer working at home because you are under someone's control, or...?" I thought this would make her easier to answer, but, this was a leading question that subconsciously affected her opinions. Instead of asking this, I could say "why do you prefer working at home?" Overall, my questions were too specific and failed to attempt the informant to say more about herself spontaneously. What I can do next time is use the questions Spradley lists as reference, focus more on their experience, and aim to develop the "interview" into a conversation that we can talk about easily.

\section{Positionality 1}

In the previous interview, I positioned myself as a high school student in both settings, with no difference between me and other customers or students in that Institution. The only person who will think me as strange might be the clerks, because I get lots of questions that others will not be interested in, and the little girl, because she noticed that I was eavesdropping on their conversation outside. Positioning myself like that, I found it easier to observe because it could lower the defense of the strangers in order to make them behave more naturally, boosting my efficiency of writing the actual phenomena that happens in the real life. If I told them at the beginning that I came here to write a field note, it is likely that they will not show their real performance in front of me. In fact, I'm quite familiar with both places where I conducted my work. However, it doesn't affect my observation, because I have hardly any prejudice against this place due to the reason that I didn't pay much attention to the people and things in it before. The only thing affected by my history might be the person who I choose to interview. I ordered many times at a certain staff, so I thought he might trust me more as he probably remembered me. I guess I will try more staffs with my interview later.

\section{Positionality 2}

\section{Week 1 (restaurant)}

Overall, due to the familiarity I had with other similar places with the settings, I was quite comfortable in the restaurant. However, I would say I wasn't very natural or fit in it because of the field note I was doing. When I was doing my observation (fingers typing on my phone, head down, elbow against the table) the majority of customers in the restaurant were either enjoying the meal or chatting with their companions. In comparison, I seemed to be an exception that was interested in neither thing. This contrast, as I mentioned, made my observation less 
natural, possibly causing the suspicion from my observant to me. Another thing is that, because the meal looked really tantalizing and the dinner was for celebrating my early birthday, I had to repress my eagerness for the food while I'm writing the field note. In other words, I was slightly rushing to finish the notes because by then I can enjoy the meal, thereby I might avoid going into too much detail for my observation. For future study, I will pre-arrange a time to conduct fieldwork with a clear and only purpose of writing field notes. I think this would help me to be more concentrated and immersed.

\section{Week 2 (quarantine hotel + auto-ethnography)}

This time the space and actors of my site are quite unique. Instead of trying to "fit into" the group, I am the "group" myself. I feel like I'm writing a diary but from two perspectives. Normally, pure descriptive and emotional reflection would be intertwined in my own diary, yet this time I separate them. I used a third-person perspective to write the descriptive note but still with the pronoun "I" and write the respective one as a judge of the "Michelle" in the descriptive note. Discussing the familiarity with the site, I think it's quite high as I've been quarantined in Shanghai before and I've been to various hotels in my life, so it only took me a short time to get used to the environment. In this field, less assumptions were made because I knew my feelings and thoughts very clearly. However, this self-observation may also be a lack of objectivity because I couldn't provide much evidence of why I would think this way or from which fundamental concept I came up with this thought. Furthermore, because every day in quarantine seems to be the same, sometimes I would fail to memorize everything in correct orders and details. In this situation, I think I'd better have someone to observe me and record, or I should be the observer.

\section{Week 3 (quarantine hotel + interview)}

I'm the informant's older sister so I'm quite familiar with her, which also means that I might have some bias toward her that I'm not aware of. I might have some assumptions on her answers which stop me from really listening to her responses and making good follow up questions. I started the conversation mainly for the purpose of finishing the assignment, so my attitude may also affect the overall quality. Next time, I think I should choose another site and informant to conduct an interview, as ethnographers often do. The interview is conducted in a place that we already spend 10 days in and to the informant, I'm a person that she is very familiar with, thus the overall setting is safe. However, because of identity and my question is somehow linked to her academic performance, she might be pressured a bit and feel reluctant to tell her true thoughts. Next time I should spend more time in the beginning to guide the informant and ask for permission. During the interview there were several (awkward) silences in which I didn't know what to say. To prevent that, I should've prepared more questions beforehand and ensure they are efficient and easy to expand on.

\section{FINDINGS}

\subsection{Preliminary findings 1}

Here's an example of what I noticed from the previous note in the English institution: I see a girl in a pink dress walking out of the elevator alone herself. She fiddles with his bracelet and walks slowly to the classroom, even humming a song in her mouth, and she certainly doesn't seem to be in a hurry to go to class. My attention was immediately caught be her actions instead of the designs on her cloth. I guess maybe it's because I'm subjective about what I want to focus on. Compared with clothes, the humming and fiddling bracelet can reflect more about her attitudes toward learning and her state. So, what I was not noticing was what song she was humming. As I recalled, the tone was familiar to me, but I didn't pay attention to it because it was not helpful for what I was going to research about. I assume she just not that care about her class or she is going to the next class, which is not begin according to all her action. However, I cannot confirm which theory is true because I didn't have more evidence to rule out some possibilities. Just from observing the surface of things is not that helpful, but it was the only thing I can do. If I can, I would love to know where she was heading to.

Also, here's another instance from my fieldwork in the coffee shop: A teenage couple is sitting at the corner of the coffee shop. I deduct it from their ages and intimate behaviors, including some physical contact and the smile. They do not seem like really doing homework here, because they just sit and chat. Too far apart, I can't hear what they are saying, but seeing their smile. It is quite interesting that two women first decide to sit next to the couple. After they sit down, one of them glance the couple quickly and whisper something to another girl. They turn their eyes at the sweet behavior of the couple next to them then stand up to leave. I noticed at basically the behaviors to deduct their relationship, as I mentioned in my note. Also, I paid my attention on the reaction of the people next to them in order to find out the attitudes toward couples of other people. I seldom noticed the wearings of them because those were useless for me to make a judgment. On the other hand, if my topic was about which group of people dislikes couples extremely, the attention on people's wearing would be important as I will have to judge which group, they belong to. I assume that people might generate the feeling of jealousy towards couples from their eyes rolling or the feeling was produced from my experience of me myself seeing young couples. I would really love to explore this topic about whether the people degree of jealousy towards couples have something to do with ages. 


\subsection{Preliminary findings 2}

Unfortunately, I didn't have the opportunity to stay in one setting to conduct careful investigation, however, I did learn something from the fieldworks and I will be using my restaurant fieldwork as an example:

Week 1 (restaurant):

During the observation, I first took a grand tour of the whole restaurant in order to give a brief description of the environment. I think for this part my attention was distributed quite evenly as I not only depict the views inside and outside the restaurant, but also described other senses such as "my nose can't capture a strong smell of the food, but my ear can hear the soft and comforting nonlyric music playing in the background." However, when I shifted my focus to people, I noticed that I tend to ignore the waiters probably because they were to natural in the setting (it was after I finished everything else that I realized I had missed the waiters). Instead, my eyes were more likely to be caught by the community that I wasn't very familiar with. For example, I went on dates with my boyfriend and had family dinners with my parents and siblings frequently, thus I found myself was less interested in the tables that sat "couples" or "family" with children. Adversely, because I rarely spent time with elderly, I chose a "family" that includes old people eventually to do detail observation. The reason why I put quotation mark on these words is because these relationships were all out of my assumptions. I didn't walk up to ask but only deduce based on their interaction and languages. For instance, I guess table 1 was a couple according to the treacly atmosphere between the boy and the girl, in which they smiled, laughed, exchanged eye contact a lot and physical contact also happened. I thought my target was a family with two pair of couples, one old and one in middle age, because the younger man was concerning about the old man's health by saying things like "don't eat too much, your stomach isn't that strong" and their ages matched with this assumption. The females didn't eat too much and while they were eating, they behaved decently with slow motion and control in the sounds they make. The males, one was talking for most of time in a relatively loud voice which could send his words to my ears, and another was eating quickly and a lot. I wondered if the women didn't have great appetite or, to put in a greater context, were more restricted by social requirements on manners. For instance, when I was a child, I was asked to follow a lot of table rules, such as both hands must be on the table, no talking with mouth instead, eat slow and don't get too much food at once. However, my brother was asked to do similar things, but because of his rebellious personality, he rarely listens. Because I mainly focused on their table, I didn't notice any eating behaviors of people in other ages although they were all presented in the restaurant at that time. If I got a chance, I would be interested in observing more behaviors of people while they are eating with fixed time and population to observe.

\section{ANALYSIS}

\subsection{Reflection}

Knowing what you are noticing or not noticing is crucial, because you can figure out what you are really interested in by knowing where your selective attention went to during the whole process. If your attention went to the clothing, for instance, it is likely you are focusing different things compared with people noticing behaviors. The focus of your observation has a great influence on the topic you will write. The details you are noticing can make a difference on what you are writing. From my previous writing, I focused a lot on the response of clerks towards different consumers. So basically, my attentions went on the consumers and clerks who would interact with the customers instead of the cleaning person. If I choose to focus on the cleaning person, it would be another story. Anyway, during the daily life, people tend to focus on what they want to know instead of anything, so knowing what you tend to focus can help you have a better understanding of yourself. You can ditch out your potential opinions on some social issues. Maybe it's something that you think you're neutral. After learning that what you tend to pay attention to (what you are noticing and what you are not noticing), you will know that you are just focusing on a certain aspect without seeing it all. So, in life, this may help you know your potential thoughts, or it may help you see the whole picture of things with a better view. It is beneficial to know what you are not noticing in your daily life in order to generate new thoughts.

\subsection{Personally view}

Reflecting on the process of how I chose to describe the setting and settling down on the target observant expanded my knowledge on the way I made decisions and considered things. When I realized I was more interested in observing older people, I suddenly thought of how seldom I call or visit my grandparents in the past few years. Looking at their interaction, I wonder if one day my parents will also be asked to eat less, or they will enjoy dinner together by themselves. Which option do I prefer? What do they want? I would like to ask them these questions because during the observation, I didn't notice the reaction of the old man when he was asked to do something. From this, I conclude that one importance of reflecting on what we notice/don't notice is how it sometimes provides a brand new perspective of viewing the world, which may inspire you to question things you rarely thought of and eventually come up with patterns about the society. This process is totally different from learning things from a book or being told by someone else. The knowledge extracted from reflections is what is 
authentically original, thus it is something priceless and would be remembered for a longer time.

\section{CONCLUSION}

During this ethnographic study, I learned a lot. To my surprise, it is not that difficult for me to understand, for instance some tangling social issues, as I assumed to be at the first place. Instead, it is to make judgments from observation of daily life. It only requires you to have patience in order to generate thoughts from what you see. Also, it is thought-provoking to see the attitudes from staff towards the people who refuse to take orders. As I wrote in my note, it said that: "Would you mind if a customer came in but didn't order?" He shakes his head, sneers, and denies this possibility. "After all, this is not my coffee shop, and his profit has nothing to do with me. Ijust want to be comfortable." To my surprise, his answer is different from what I expected. I thought they can be mean to the person who doesn't order anything because they are taking a free spot for free. Turns out, they don't even notice this phenomenon. It is also interesting to see how self-center people can be because they only care about their benefits instead of the whole shop. From the talking, I also learned a new marketing strategy of not kicking out customers who don't order in order to make the coffee shop look more crowded and attract more customers. So I guess it is also educational for me to conduct the fieldwork. Soon, I might proceed with this project as I'm really curious about this topic and I will try to talk to people more to get more useful information. This class teaches me how to separate my assumptions and the facts that I observe, and I learned the thoughts generated from my mind are not taken for granted. Instead, this is a slow process which happens in our mind. During ethnographic work, the key is to feel this slow process which I really enjoy. I tend to judge things by observing instead of immediately making conclusions. What I am still confused now is to understand whether gender can influence the attitudes of clerks. So far, I didn't see this phenomenon, but I am interested in this topic. So, it is so hard for me to settle on a certain one. Also, I'm considering the positionality between me and the interviewees, whether they will think I'm strange for asking too much, or I will get little information from them. It is hard to balance these two elements. I also learn that patterns cannot be concluded by only some simple phenomena according to what we observe weeks ago, because they are only simple observations instead of a thorough one lasting for years. To find out a certain pattern. I must commit myself into the whole ethnographic work to really get a conclusion from confirming the evidence with different groups. Also, besides what I learned in this course; I get to know some good friends. Staying with friends and professor to study really facilitate my learning through absorbing new ideas from each other. I will always remember to stay curious in the whole process of ethnography in order to perceive lots of surprising facts from the things that I am interested in.

\section{1. discussion}

\section{- What surprised you?}

At the very beginning, I was surprised plainly because of the existence of this subject/research method due to contradictory characteristics. Ethnography can be both a process and a product as we may "do ethnography" as well as "write ethnography" after the data collection. Ethnography may be considered as a "easy" study because it seems that no abundant background knowledge about a certain group of people is needed, and sometimes too much personal understanding can be influential on the objectivity of the field notes. Meanwhile, ethnography is also complex. Because ethnographers are studying human beings in social and cultural settings, there are too many fluctuant variables to be considered and observed. In such a complicated context, I was really surprised by the sophisticated and comprehensive field note and interview guidance Ethnographer such as Emerson and Spradley can produce.

- What did you find most interesting, exciting, or useful?

- I like how ethnography makes observing people a meaningful thing and allows people to develop a rich and valuable understanding of the cultural meaning of practices and interactions.

- I like the contradictory characteristics of the positionality of the researchers because although we aim to immerse ourselves into the setting and see things from an insider's perspective, our lack of understanding of the culture or our bias are meanwhile inevitable.

- I also found the practicality and flexibility of ethnography interesting, exciting, and useful. For example, it was fascinating for me to see that, in "How I Learned What a Crock is",[2] how Becker, an intellectual ethnographer from University of Chicago, turned out to have "very few little idea" about the new site he's entering in the beginning, then gradually learned more and more about it by following the students with a very special identity, and eventually found out an important motivation of medical students.

\subsection{Future work}

I will be taking the mindful observing method into the future as a way of interacting with fresh knowledge. In this course, I really slowed down my pace in my daily schedule to look carefully as I rarely did into something simple as a tree, or complex as a whole restaurant. It wasn't comfortable in the beginning as I failed to 
recognize the meaning behind it. I did the first observation and wrote up with sundry thoughts filling my mind, including confusion, doubt, and amusement. However, after a few trials, I was surprised by how I subconsciously started to observe something and try to summarize a pattern from it. For example, because I did some watching in the restaurant, I would observe people in the cafeteria when I finished earlier than my friends. One day, I found that it seemed that boys would approach the food by lowering themselves, while girls would uplift the bowls to send the food to their mouth. It might not be true, but the feeling of finding a pattern was unique. Besides, the ability to view things neutrally and with infinite curiosity is also what I believe to be useful for my future academics.

\subsection{Recommendation}

I was still unclear about the process of conducting ethnography research, especially the process of coming up with a research question. How big should the question be? How would the question determine the range and things ethnographers focus on during their fieldwork? Do they change/expand the question during the observation? Or the question is not that important and ethnographic research could actually be started with simply a target site or population? Besides, I would also love to know more about coding. As professor mentioned frequently, ethnographic research often takes up to years to finish, in which a significant amount of field notes was produced, therefore an efficacious organizing system would be obviously vital. I think this skill would be also helpful in other areas of daily life.

\section{REFERENCES}

[1] Thorne, B. (1990). Children and gender: Constructions of difference. In D. L. Rhode (Ed.), Theoretical perspectives on sexual difference (pp. 100-113). Yale University Press.

[2] Becker, H. (2010). How i learned what a crock was. In Atkinson, P., \& Delamont, S. (Eds.), SAGE qualitative research methods (pp. 29-35). SAGE Publications, Inc., https://www.doi.org/10.4135/9780857028211

[3] Anne M. Jeff B. Murray, and Elizabeth H.(1998) The Tattoo Renaissance: an Ethnographic Account of Symbolic Consumer Behavior. in NA - Advances in Consumer Research Volume 25, eds. Joseph W. Alba \& J. Wesley Hutchinson, Provo, UT : Association for Consumer Research (pp. 461-467). , https://www.acrwebsite.org/volumes/8195/volumes /v25/NA-25

[4] Hill, Ronald Paul; Gaines, Jeannie.(2007) The Consumer Culture of Poverty: Behavioral Research Findings and Their Implications in an Ethnographic
Context. The Journal of American Culture; Malden Vol. 30, Iss. 1 (pp.81-95), https://www.proquest.com/docview/200589962?pq -origsite $=$ gscholar $\&$ fromopenview $=$ true

[5] Michiko, Amanda, and Shigihara. "A 'Professional Back Place': An Ethnography of Restaurant Workers." CU Scholar UNIVERSITY LIBRARIES, $\mathrm{U}$ of Colorado Boulder, scholar.colorado.edu/concern/graduate_thesis_or_d issertations/ 2227mp980. Accessed 27 Oct. 2021. 